\title{
PARTICIPAÇÃO DA ENFERMEIRA EM COMISSÃO TÉCNICA DE MATERIAL HOSPITALAR
}

\author{
Heloniza de O. Gonçalves Costa ** \\ Maria José Arleo B. Amorim **
}

RBEn/09

COSTA, H.O.G., AMORIM, M.J.A.B. - Participação da enfermeira em comissão técnica de material hospitalar. Rev. Bras. Enf.; DF, 31 : 525-536, 1978.

\section{INTRODUÇAOO}

Em administração, o fator "material" merece considerável importância porque sem estar devidamente equipado, nenhum serviço poderá desenvolver suas funções.

O movimento de Racionalização do Trabalho deu origem à várias atividades relacionadas com material e no Serviço Público, antes deste acontecimento, utilizava-se os bens sem critérios de organização. A partir daí, a legislação fol enriquecida neste sentido, favorecendo dirigentes e funcionários das empresas.

No Hospital Ana Nery, do INAMPS, foi criada a Comissão Técnica Hospitalar de análise e julgamento de Processo de Material Médico, considerando as características e peculiaridades deste nosocômio.
No início da gestão da atual chefia do Serviço de Enfermagem em 1975, houve a preocupação de responsabilizar enfermeiras assistentes pela previsão, organização e controle de todo material técnico, dentre outras tarefas administrativas.

No presente trabalho, expomos o nosso plano de atuação no que se refere a requisição, recebimento e responsabilidade pelo preparo, utilização e controle de todo o material técnico.

Focalizamos também a importância da enfermeira na referida Comissão quando procura escolher o material que atende às necessidades do serviço por sua qualidade e rendimento em consonância com os outros interesses da Instituição.

Queremos ressaltar ainda que em todas as nossas atividades, contamos com o apolo e colaboração da chefe do Serviço de Enfermagem, que com seu di-

* Tema Livre apresentado no XXX CBEn em julho de 1978.

* Assistentes da Chefia do Serviço de Enfermagem do Hospital Ana Nery - Salvador Bahia. 
COSTA, H.O.G., AMORIM, M.J.A.B. - Participação da enfermeira em comissāo técnica de material hospitalar. Rev. Bras. Enf.; DF, 31 : 525-536, 1978.

namismo e eficiência ajuda a esclarecer as dúvidas suscitadas.

\section{I - CONSIDERAÇÓES GERAIS}

A Ordem de Serviço n.o SAM-039.13, de 11 de junho de 1976 criou a Comissão Técnica de Material Médico-Hospitalar, nas Subsecretarias Regionais de Assistência Médica do INAMPS; constituem a aludida Comissão, um médico, uma enfermeira e um servidor administrativo.

Incontestavelmente, a atuação da enfermeira é importante em todo o pro cesso de aquisição, desde a identificação de materiais necessários à sua unidade de trabalho, até a experimentação e uso dos mesmos nos Serviços de Saúde.

Por exigências de ordem administrativa, foi formada no Hospital Ana Nery uma Comissão Técnica Hospitalar de análise e julgamento de Processo de Material Médico e fomos indicados para a sua composição como membros efetivo e suplente pela chefia do Serviço de Enfermagem. Como veremos adiante, as atividades que até então realizávamos foram básicas para um melhor desempenho na Comissão, considerando o preparo especifico e as vivências anteriores.

O Hospital Ana Nery, pertencente ao INAMPS, dispõe de trezentos leitos distribuídos entre Cirurgia Geral, Clínica Médica e Obstetrícia, contando também com os Serviços de Hemodinâmica, Centro de Recuperação Operatória, Seção de Pacientes Externos (Emergência, Ambulatório, Saúde Comunitária) e Setor de Treinamento de Enfermagem. O Serviço de Enfermagem é composto de 67 (sessenta e sete) enfermeiras(os), 114 (cento e quatorze) auxiliares de enfermagem e 178 (cento e setenta e oito) auxiliares operacionais.

Considerando que o fator "material" merece uma relevante importância na realização das atividades de enfermagem, a atual chefia, em 1975, início de sua gestão, indicou uma enfermeira pa- ra responsabilizar-se pela previsão, organização e controle de todo material técnico, função que nos fol entregue em seguida, dentre outras tarefas administrativas.

Diante do exposto, pode-se notar que realizamos nosso trabalho observando o seguinte esquema:

1 - requisitamos, recebemos e controlamos todo o material técnico. Ressaltamos que para iniciarmos esta atividade tivemos de sistematizar a forma utilizada, o que nos permite considerar como "organização e controle de material".

2 - participamos do processamento de compras, analisando as ofertas e emitindo parecer técnico junto com os demais elementos que compōem a referida comissão.

1 - Participação na Organização e Controle de Material

De início pareceu um trabalho difícil, uma vez que se trata de um hospital de grande porte em fase de expansão, onde sua planta física e estrutura organizacional não facilita tal atividade. Fizemos, primeiramente, um reconhecimento da situação de todo material hospitalar existente nas unidades, como também obtivemos informes das condições em que se encontrava o almoxarifado.

Para isto, realizamos, durante cinco dias consecutivos, visitas às reservas de todas as unidades, quando registramos todo o material existente. Com a intenção de facilitar a execução da tarefa, elaboramos um plano específico yara material de consumo e outro para material permanente, já que é esta a classificação mais comumente adotada.

\subsection{Organização e Controle do Material de Consumo}

Material de consumo é aquele que tem duração prevista de, no máximo, 2 (dois) 
COSTA, H.O.G., AMORIM, M.J.A.B. - Participação da enfermeira em comissão técnica de material hospitalar. Rev. Bras. Enf.; DF, 31 : 525-536, 1978.

anos, que é consumido pelo próprio uso ou se destina a substituição de peças, sobressalentes ou acessórios.

Com referência a este material, pudemos observar os seguintes aspectos.

- Todas as reservas estavam desarrumadas, dificultando a identificação do material existente.

- Os excessos encontrados em algumas eram inconseqüentes, apresentando estoque suficiente para suprir os gastos por muito tempo.

- Várias unidades não dispunham de local apropriado para "a guarda do material que era distribuído em armários improvisados sem as condiçōes básicas necessárias.

-A pouca experiência e insuficiente atuação das secretárias de ala, funcionárias responsáveis pelo pedido de material e arrumação das reservas, possibilitavam a existência de falhas neste sentido.

Detectados os problemas, adaptamos o nosso plano de ação com o objetivo de solucioná-los, cujas etapas encontramse a seguir:

a) organizar todas as reservas;

b) controlar os pedidos de material das unidades, redistribuindo os excessos.

c) elaborar novas previsōes de material.

Para que o plano fosse devidamente executado, solicitamos inicialmente o apoio das colegas. A participação efetiva das secretárias de ala seria imprescindível, pois é este o elemento da equipe de enfermagem que lida diretamente com a requisição e a ordem de todo o material.

Em reuniōes ordinárias e uma extraordinária com as enfermeiras(os), expomos o esquema de trabalho, solicitando sua colaboração no sentido de supervisionar mais freqüentemente as atividades da secretária, de controlar melhor e evitar o uso indevido do materal e de manter arrumadas as reservas.

Após este contato com as colegas, reunimos as secretárias para colocá-las a par da situação e posicioná-las na execução do plano de trabalho. Nos intervalos entre as etapas, foram realizadas reuniōes com as mesmas para discussão e orientação sobre as dúvidas suscitadas até então.

\section{a) organização das reservas}

Sorteamos uma unidade para servir de "reserva padrão" e a organizamos, obedecendo critérios previamente adotados, a partir de experiências vividas e de leituras referentes ao assunto.

Estes critérios foram redigidos (Anexo n.o 01) e distribuídos em reuniāo com as secretárias(os) e oportunamente estas foram convidadas para uma visita à reserva padrão que deveria ser tomada como modelo.

Procuramos oferecer melhores condicóes às reservas de todas as unidades, como por exemplo, quanto à instalação de prateleiras, ao aumento do número de armários, à troca de fechaduras etc.

b) controle dos pedidos e redistribuição dos excessos.

Para que todo o material excedente fosse redistribuído e alnda com o propósito de evitar novo acúmulo de material nas unidades, sentimos necessidade de nos posicionar entre estas e o almoxarifado durante, pelo menos, 6 meses.

Ficou então estabelecido que as Nozas de Suprimento de Material deveriam ser visadas pela chefia de Enfermagem e depois entregues ao almoxarifado. Ao chegarem na chefia, todos os pedidos eram analisados, isto é, realizávamos uma comparação entre estoque, previsão e quantidade solicitada; alterávamos esta última, caso fosse observado suficiente estoque para os gastos do mês 
COSTA, H.O.G., AMORIM, M.J.A.B. - Participaçāo da enfermeira em comissāo técnica de material hospitalar. Rev. Bras. Enf.; DF, 31 : 525-536, 1978.

ou ainda se o estoque mais quantidade pedida ultrapassassem a previsāo. Durante esta análise, excluíamos do pedido todos os materiais que constavam da relação dos excessos; a unidade que possuía excedente enviava para a unidade solicitante.

c) elaboração de novas previsōes de material.

Constatamos que as previsōes de todas as unidades eram feitas baseadas em cálculos empíricos e com o propósito de sanar os problemas de excessos, falta de suprimento, desvios e desordem do material, estamos tentando fazer um novo cálculo com base no gasto real de cada unidade. Para isso, todas as secretárias de ala foram esclarecidas quanto a problemática e orientadas no sentido de sua resolução.

Esta etapa do plano encontra-se em realização, porque ainda não fol possível efetuarmos uma previsão exata de todos os materiais. Elaboramos um impresso para tomada dos dados (Anexo n..$^{\circ}$ ) e estabelecemos um prazo de três meses para a contagem do material.

Findo este período, calcularemos a média dos gastos mensais e teremos uma previsão baseada em critério apurado como já obtivemos com relação à grande parte do material.

\subsection{Organização e Controle do Material Permanente}

Material Permanente é aquele que tem duração superior a 2 (dois) anos e é inconsumível pelo simples uso, inclui também equipamentos e Instalaçōes.

Por suas próprias características, conforme observamos na definição, é mais facilmente controlado, embora exija uma supervisão rigorosa porque os danos e utilização inadequada trazem piejuizos maiores; além disso, para a sua, aquisi- ção, é necessário burocracia mais complexa.

A maior dificuldade de controle deviase ao fato de serem efetuadas trocas entre as próprias unidades e às vezes, retirada do material de uma unidade para outra, o que impossibilitava a chefia de saber onde encontrá-lo e em que quantidade, sobretudo aqueles de menor peso e de fácil transporte.

Várias tentativas foram estudadas para resolvermos o problema. Inicialmente, solicitamos que as chefes de unidade relacionassem todo o material existente e exigissem das secretárias que diariamente no período da manhã, fizessem revisão dos mesmos. Esta medida não surtiu muito efeito porque nos outros períodos o controle continuava difícil.

Elaboramos então um mapa (Anexo n. 03 ) onde relacionamos todo o material de acordo com as unidades. Este impresso fol preenchido conforme a relação de material existente em cada unidade, enviada pelos respectivos chefes. Depois de devidamente elaborado, visitamos cada unidade e ratificamos a existência do material.

Assim, obtivemos uma visão global de todo material permanente e com facilidade podemos agora localizar qualquer um deles e ao mesmo tempo verificar onde há carência oú excesso.

Já que notamos maior facilidade no controle, adotamos o mesmo sistema para a organização das previsōes. Estas são elaboradas anualmente por todas as unidades e após análise e avaliação junto ao mapa de material existente, transcrevemos para o impresso apropriado (Anexo n.o 04). Assim obtemos a relação de todo material solicitado por unidade e consequientemente adquirimos o total. Baseadas neste resultado, elaboramos um só pedido e enviamos ao Setor de Compras. Por sua vez, ao chegar o material, facilmente podemos identificar o setor solicitante. 
COSTA, H.O.G., AMORIM, M.JAB. - Participação da enfermelra em comissăo técnics de material hospitalar. Rev. Bras. Enf.; DF, 31 : 525-536, 1978.

2. Participação direta na Comissão Técnica Hospitalar de Análise e Julgamento de Processos de Material Médico.

Considerando as características e peculiaridades, do Hospital Ana Nery, as aquisiçōes de material médico-hospitalar são realizadas através de licitaçōes no próprio local e não na Superintendência Regional, pelo serviço de material, da Secretaria de Serviços Gerais e do Patrimônio, como ocorre mais freqüentemente.

Como fol referido no capítulo "Organização e Controle do Material", encaminhamos inicialmente ao Setor de Material as requisiçōes completas e com especificação correta. Para que haja uma atuação eficiente, sentimos necessidade de interpretar todo o andamento do processo até o momento da nossa participação direta.

A partir do recebimento das requisiçōes, o Setor de Material codifica os pedidos, já que os materiais obedecem à nomenclatura, classificação e codificacação já estabelecidos; observa-se estes critérios em todos os documentos específicos de material usados na Instituição. O Setor de Material elabora a Previsão de material permanente e de consumo. o Setor de Compras atribui estimativa de custos, totalizando quantidades e valores, após análise das classificações contábeis. O Setor de Material depois da adequação às dotações orçamentárias disponíveis, elabora o Plano de Aquisição de Bens Móveis (PABM). Após a aprovação do $\mathrm{PABM}$, é feito o pedido de compra de material (PCM) pelo setor de Material que o encaminha ao Setor de Compras. Este Setor dá abertura ao processo, encaminhando-o à Superintendência, onde é protocolado e numeraco, sendo devolvido posteriormente ao Hospital Ana Nery.

O Setor de Compras yrepara a licitaçãu e emite pera as firinas, atravís de recibos. Licitação é o procedimento administrativo mediante o qual a Administração Pública seleciona a proposta mais vantajosa para o contrato de seu interesse". O procedimento de licitação está sujeito a três modalidades: Concorrência, Tomada de preços e Convite. O tipo de modalidade de licitação é estabelecida pelo valor aproximado da despesa. Na licitação para compra, o setor competente especifica o objeto a ser adquirido, assim como quantidade do mesmo e condições exigidas. "As especificaçōes de material são declaraçōes formuladas, definidas e completas do que o comprador exige do vendedor. Ainda com o Setor de Compras é preparada a ata de encerramento da licitação, anexadas as propostas das firmas e elaborado o mapa-resumo.

Nesta situação, o processo é encaminhado à Comissão Técnica Hospitalar de Análise e Julgamento de Processos de Material Médico para estudar as ofertas e emitir parecer técnico.

Cabe à enfermeira, entre os demais elementos técnicos, escolher o material que melhor atenda ao interesse do Serviço. Essta fase é, sem dúvida, aquela que exige mais maturidade porque como toda avaliação, implica em utilização de critérios objetivos e impessoais.

0 art. 133 do Decreto-lei 200/67, declara que na fixação dos critérios de julgamento das propostas, deve-se levar em conta, no interesse do Serviço Público, os fatores de qualidade, rendimento, preços, condições de pagamento, prazo de entrega e outras que possam ser estabelecidas no Edital. Edital é o instrumento através do qual a Administração leva ao conhecimento público a abertura da concorrência ou a tomada de preços, fixa as col.dições de sua realização e convoca os interessados para a apresentação de suas propostas".

Para facilitar esta fase do processo, adotamos como medida a organização 
COSTA, H.O.G., AMORIM, M.J.A.B. - Participaçáo da enfermeira em comissão técnica de material hospitalar. Rev. Bras. Enf.; DF, 31 : 525-536, 1978.

de uma reserva com diversos tipos de amostras e pastas com catálogos ilustrativos de materiais. Elaboramos também um impresso apropriado para controle dos testes de material (Anexo n. ${ }^{\circ}$ 05) e orientação para o preenchimento do referido impresso (Anexo n. ${ }^{\circ}$ 06).

A organização das amostras e das pastas visa 0 reconhecimento dos objetos em concorrência porque as firmas quando repetem sua participação em processos com o mesmo material nem sempre enviam amostras juntamente com as propostas. Nesta reserva, encontra-se um classificador contendo informaçōes fornecidas por enfermeiras das diversas unidades sobre várias marcas de material.

A firma deve apresentar número suficiente de amostras caso o material seja desconhecido e fazemos o devido encaminhamento para uma ou mais das unidades com o objetivo de ser testado por colegas que lidam diretamente com 0 mesmo. Quando o material é conhecido, mas é sujeito a possíveis variações de qualidade, as amostras são também enviadas às unidades para teste.

$O$ resultado dos testes é registrado no impresso apropriado constando de características verificadas de qualidade, aplicabilidade e durabilidade do material. Teremos assim subsídios para o confronto entre as marcas.

Para determinados tipos de material permanente, solicitamos a opinião de colegas que os utilizam em outras Instituições de Saúde. Cada aparelho ou instrumento é selecionado pela potência, manutenção e eficiência.

Segundo Victória Secaf, para aqueles materiais que exijam segurança para o paciente quanto às condições de fabricação e esterilização, seria aconselhável uma visita de vistoria às fábricas pelos membros da comissão. Exemplo: fios cirúrgicos, equipos, seringas e agulhas descartáveis.
Quando coincide o material de boa qualidade apresentar também menor cotação, a emissão do parecer não traz dificuldades. Mas, nem sempre o material escolhido corresponde ao menor preço; neste caso, fazemos a justificativa no processo das razões da escolha pela qualidade, conforme estabelece a legislação que serve de base para as Orientaçōes do INAMPS neste sentido.

Em determinadas situações, apenas: uma marca de material é aceita pelas equipes; neste caso, é imprescindível que haja uma convincente justificativa técnica, assim como quando existe restrição a uma única marca apresentada.

Observamos então que nesta fase, de julgamento, fazemos a análise do mapa de propostas dos fornecedores e fazemos a leitura detalhada da especificação do material oferecido por cada um deles. Nesta oportunidade, comparamos o oferecido com a especificação constante no Edital, o que muitas vezes recomenda a exclusão do material de vários fornecedores por não corresponderem às especificaçōes exigidas.

Algumas vezes, sentimos necessidade de recomendar redução de quantitativos, o que ocorre quando o material usado durante determinado período não atinge a previsão, e o estoque existente é superior ao que se esperava.

\section{CONCLUSAO}

Neste trabalho, que aqui é concluído, tivemos a oportunidale de expor a nossa forma de atuação como enfermeiras responsáveis pela previsão, organização e controle de todo material técnico do Hospital Ana Nery e a nossa participação no processo de compras como elementos da Comissão de Material Técnico Hospitalar, analisando as ofertas e emitindo parecer.

Com relação ao primeiro aspecto, mostramos como trabalhamos com material 
COSTA, H.O.G., AMORIM, M.J.A.B. - Participação da enfermeira em comissão técnica de material hospitalar. Rev. Bras. Enf.; DF, 31 : 525-536, 1978.

de consumo e com material permanente. E quanto ao segundo aspecto, apresentamos os critérios adotados para responder os processos com justiça e lealdade.

Esperamos que estas medidas favoreçam não somente à equipe de saúde dispondo de todo material necessário às suas atividades, como também à Instituição pelo uso racional de todo o material e principalmente ao paciente que recebe os benefícios decorrentes de um planejamento mais eficiente.

\section{CRITERIOS PARA ORGANIZAÇAO DAS} RESERVAS (PARA ORIENTAÇAO DAS SECRETARIAS DE ALA)

Antes da arrumação propriamente dita, temos alguns pontos a considerar:

1. O local destinado a guarda do material deverá ser de fácil acesso, sem umidade, bem iluminado e permanentemente limpo.

2. O material deverá ser agrupado de acordo com sua finalidade.

3. As embalagens deverão ser mantidas caso tenham indicação do tempo de validade do material e/ou tenham a finalidade de proteger o material de prováveis contaminações ou danificaçōes.

4. O material descartável deverá ser colocado em prateleiras mais altas. Mantê-los sempre na embalagem.

5. Na parte anterior das prateleiras colocar-se-á a identificação do material ali depositado.

\section{COMO ARRUMAR:}

- Os impressos serão colocados em prateleiras afins, separados por tipo e obedecendo a ordem numérica (número do impresso).

- O material de escritório deverá estar próximo e logo abaixo ao local destinado aos impressos.

- O material descartável ficará também em prateleiras afins agrupado de acordo com o tipo do material e, em caso de haver numerações indicadoras de dimensões, a arrumação obedecerá a ordem numérica crescente ou decrescente.

- As soluções para uso parenteral deverão ser colocadas em prateleiras próximas, nunca colocar dois tipos de soluções em uma única prateleira.

- As soluções desinfetantes obrigatoriamente ficarão bem distantes de qualquer outra solução e em prateleiras próximas ao piso.

- As soluções antissépticas deverão ter lugar distinto bem distante das soluções parenterais e dos desinfetantes.

\section{ANEXO N. 1}

- As soluções destinadas a enemas deverão ficar em local distante dos desinfetantes, dos antissépticos e das soluçōes parenterais.

- Os demais materiais poderão ser arrumados obedecendo os critérios gerais e sempre agrupados de acordo com o tipo. 
COSTA, H.O.G., AMORIM, M.J.A.B. - Participação da enfermeira em comissão técnlca de material haspitalar. Rev. Bras. Enf.; DF, 31 : 525-536, 1978.

HOSPITAL ANA IERY - INAMPS

SERVICSO DE ENFERMAGEMS

CONTROLE DE CONSUMO DE MATERIAL

Yats

UNIDADE:

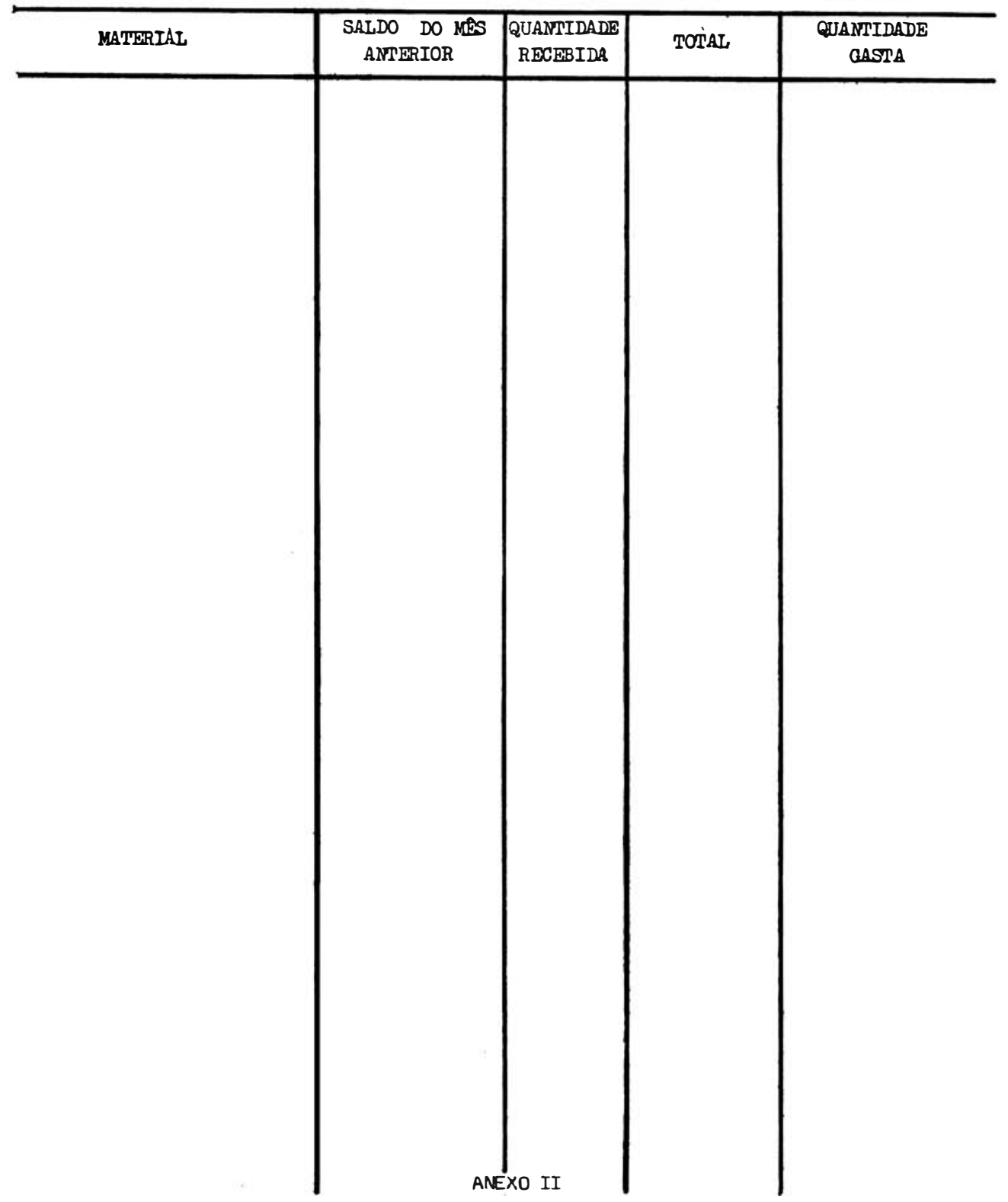




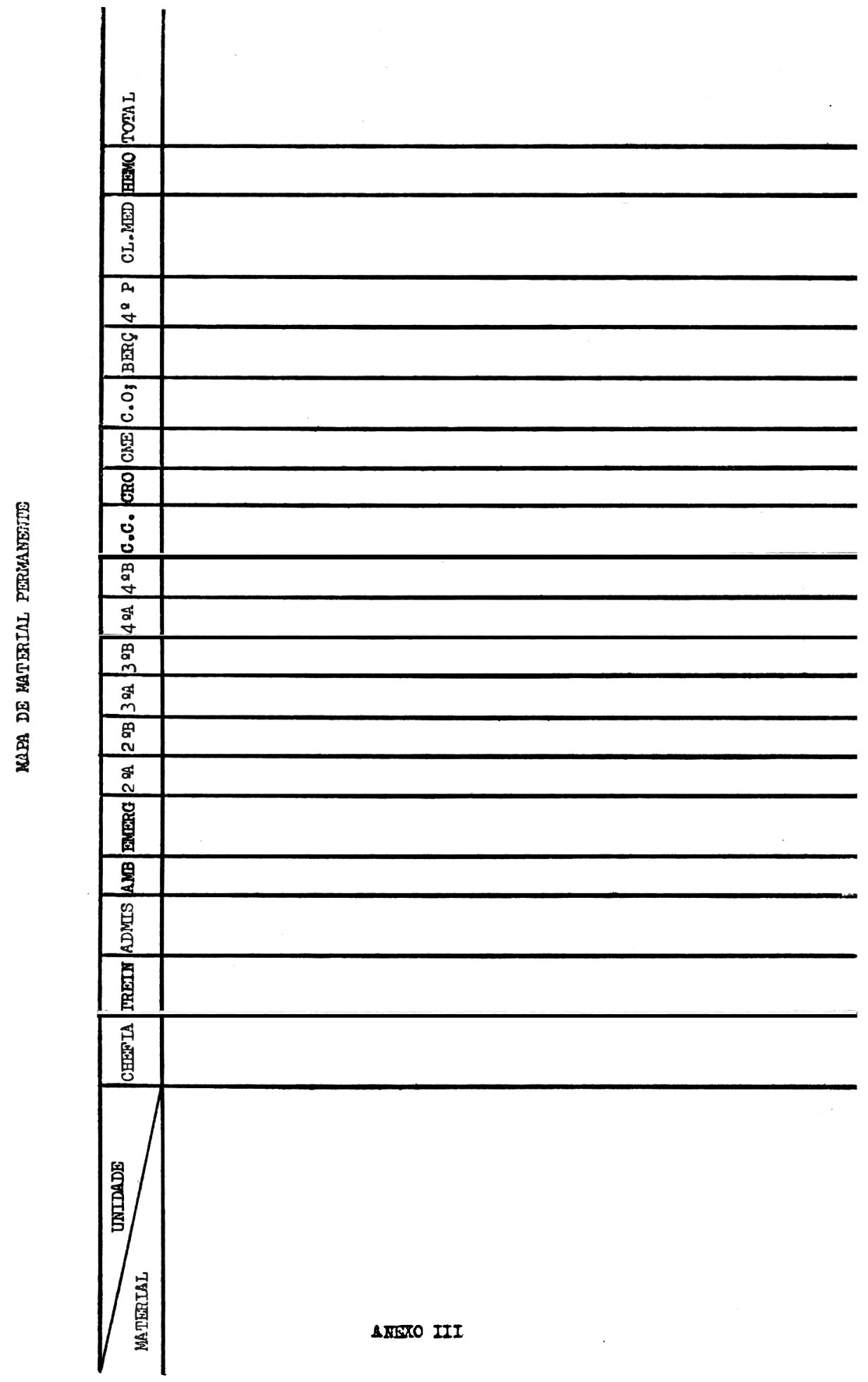




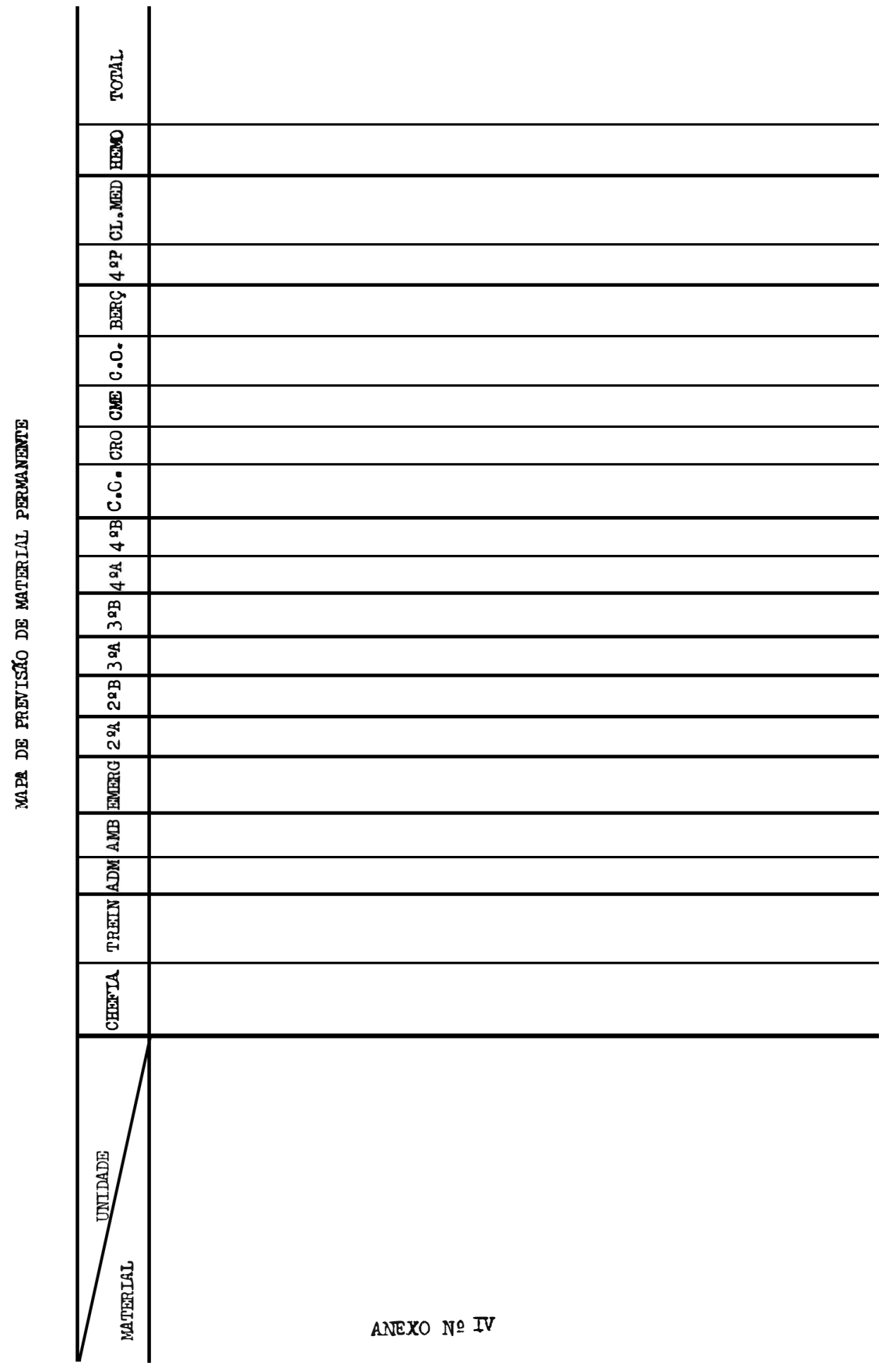




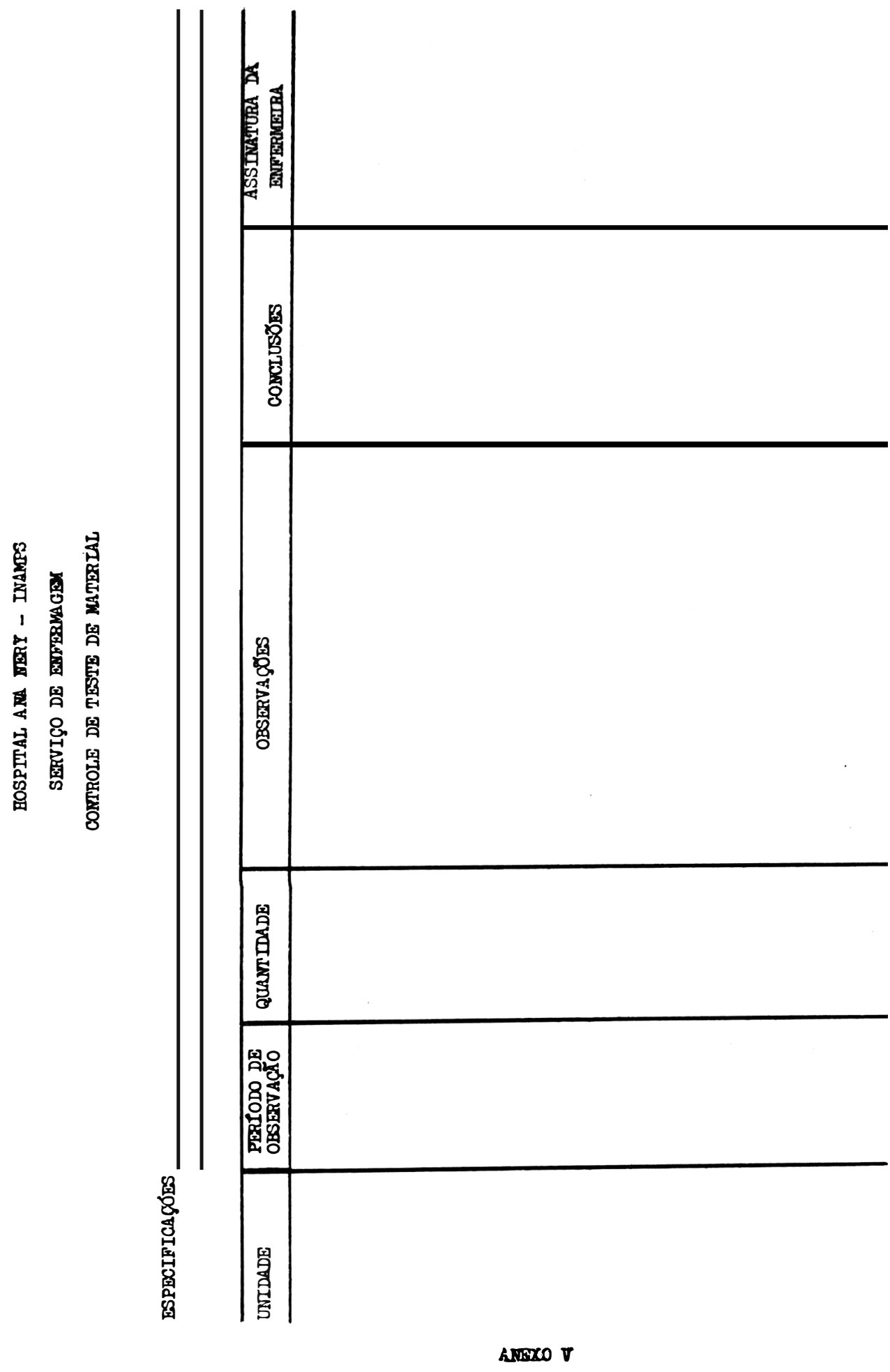


COSTA, H.O.G., AMORIM, M.J.A.B. - Participaçăo da enfermeira em comissāo técnica de material hospitalar. Rev. Bras. Enf.; DF, 31 : 525-536, 1978.

\section{ANEXO N.O 6 \\ ORIENTAÇAO PARA O PREENCHI- MENTO DA FICHA DE CONTROLE DE TESTE DE MATTRIAL}

Observaçōes: Os itens referentes à Unidade, Período de Observação e Quantidade são preenchidas pela Chefia de Enfermagem.

Os itens referentes a Observação e Conclusões são preenchidas pela enfermeira-chefe da Unidade onde é testado o material.

Quadro 1 - Unidade especifica-se o andar e a Ala em que será testado o material.

Quadro 2 - Periodo de observação coloca-se a data (dia, mês e ano em que são iniciadas e concluídas as observaçōes).

Quadro 3 - Quantidade - especificase a quantidade do material testado identificando a unidade de medida.

Quadro 4 - Observação - faz-se esclarecimento quanto à resposta do material no atendimento de seu objetivo, informando sobre durabilidade, resistência, toxidade, poder alergônico, reaçōes do paciente, praticabilidade, segurança e outros. Estas observaçōes são registradas no decorrer do período do teste.

Quadro 5 - Conclusões - emite-se o parecer final sobre o material.

Quadro 6 - Assinatura - o documento deve ser assinado pela enfermeira que responsabilizou-se pelo teste na Unidade de Serviço.

\section{BIBLIOGRAFIA}

FNDTER, Ewaldo I. H. - Administraçāo de materiais. Sociedade Beneficente Săo Camilo - Sảo Paulo.

INSTITUTO NACIONAL DE PREVIDENCIA SOCIAL - Ordem de Serviço n. ${ }^{\circ}$ SGP-012.16, de 20 de malo de 1976. Compra de Material e Contratação de Serviços.

- Ordem de Servico n. SAM039.13, de 11 de junho de 1976, Criação da Comissão Técnica de Material Médico-Hospitalar, nas Secretarias Reglonais. 399.60, de 31 de março de 1976. — De- lega competência nos assuntos referentes a aquisiçáo de material.

PRADO, Elia Pimentel - Programa de Ação da Comissão Técnica de Material Médico-Hospitalar do Hospital Geral de Goiánia - INAMPS - 1977-1978.

- Administraçåo de Material Pequeno Enfoque. - INAMPS - SAMAMU.

SECAF, Victória - Papel da Enfermeira na Aquisição de Material Técnico. Revista Brasileira de Enfermagem. - Jan.; mar., 1976. 